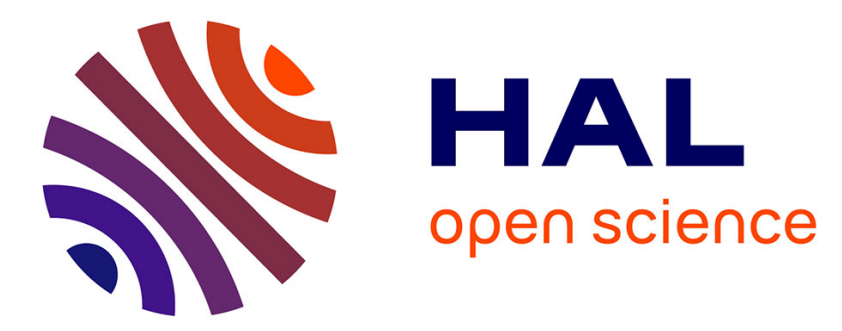

\title{
Low Power Consumption and High-Speed Ge Receivers
}

L Virot, D Benedikovic, B Szelag, C Alonso-Ramos, J-M M Hartmann, P

Crozat, E Cassan, D Marris-Morini, C Baudot, F Boeuf, et al.

\section{To cite this version:}

L Virot, D Benedikovic, B Szelag, C Alonso-Ramos, J-M M Hartmann, et al.. Low Power Consumption and High-Speed Ge Receivers. Optical Fiber Communication Conference and Exhibition (OFC), Mar 2017, Los Angeles, CA, United States. 10.1364/OFC.2017.Th1A.1 . hal-01527376

\section{HAL Id: hal-01527376 \\ https://hal.science/hal-01527376}

Submitted on 24 May 2017

HAL is a multi-disciplinary open access archive for the deposit and dissemination of scientific research documents, whether they are published or not. The documents may come from teaching and research institutions in France or abroad, or from public or private research centers.
L'archive ouverte pluridisciplinaire HAL, est destinée au dépôt et à la diffusion de documents scientifiques de niveau recherche, publiés ou non, émanant des établissements d'enseignement et de recherche français ou étrangers, des laboratoires publics ou privés. 


\title{
Low Power Consumption and High-Speed Ge Receivers
}

\author{
L. Virot ${ }^{1,2,3}$, D. Benedikovic ${ }^{1}$, B. Szelag ${ }^{2}$, C. Alonso-Ramos ${ }^{1}$, J.M. Hartmann ${ }^{2}$, P. Crozat ${ }^{1}$, E. Cassan ${ }^{1}$, D. \\ Marris-Morini ${ }^{1}$, C. Baudot ${ }^{3}$, F. Boeuf ${ }^{3}, J_{M}$ Fédéli $^{2}$, C. Kopp ${ }^{2}$, L. Vivien ${ }^{1}$ \\ 1-Centre for Nanoscience and Nanotechnology (C2N), CNRS UMR 9001, \\ Université Paris Sud, Université Paris-Saclay, site d'Orsay, 91405 Orsay Cedex, France \\ 2- University Grenoble Alpes and CEA, LETI, Minatec Campus, F-38054 Grenoble Cedex, France. \\ 3- STMicroelectronics, Silicon Technology Development, Crolles, France. \\ Authore-mail address: laurent.vivien@u-psud.fr
}

\begin{abstract}
A new $\mathrm{Si} / \mathrm{Ge} / \mathrm{Si}$ heterojunction based waveguide photodetector has been demonstrated in order to reduce the fabrication cost, increase the responsivity, and improve process robustness. State of the art characteristics in terms of dark current, responsivity and bandwidth have been obtained. Furthermore, such photodetectors were characterized in avalanche mode in order to improve the sensitivity and reduce the overall power consumption of the optical circuit.
\end{abstract}

OCIS codes: (250.3140) Integrated optoelectronic circuits; (250.0040) Detectors; (250.1345) Avalanche photodiodes (APDs)

\section{Introduction}

Silicon photonics are generating a growing interest for a large range of applications including optical telecommunications and interconnects, Quantum optics and sensing [1-4] and so on. For almost all applications, the main challenges to be solved in silicon photonics are now (i) the reduction of the power consumption and the full circuit integration cost as well as (ii) the increase in bit rates of optical integrated circuits. Germanium $(\mathrm{Ge})$ photodetectors are nowadays considered as one of the most mature devices among all on-chip building blocks of the silicon photonics platform. Indeed, Ge photodetectors offers cutting edge performances directly comparable to their III-V counterparts, this with Si technology compatibility. The state of the art characteristics are: a bandwidth higher than $50 \mathrm{GHz}$, a responsivity close to $1 \mathrm{~A} / \mathrm{W}$ at wavelengths of $1.3 \mu \mathrm{m}$ and $1.55 \mu \mathrm{m}$ according to the diode geometry, and a dark current lower than $1 \mu \mathrm{A}$ [5-9]. Whilst these photodetector characteristics are sufficient to tackle numerous applications, several challenges have still to be dealt with. That includes a reduction of the detector noise (e.g. the dark current), an enhancement of the sensitivity of the photodetectors in order to reduce the power consumption of the optical link and an optimization of the device integration in the silicon platform.

In order to address these remaining challenges, we propose a novel photodetector architecture based on a double $\mathrm{Si} / \mathrm{Ge} / \mathrm{Si}$ heterojunction (Fig. 1b). This approach (i) avoids the somewhat deleterious use of Ge in the N- and Pdoped contact regions with then specific ion implantation and metal deposition steps which are not as mature as for $\mathrm{Si}$ and (ii) facilitates the Ge photo-detector integration with the other silicon optoelectronic devices.

\section{Design and fabrication}

The germanium photodetector integration is carried out at the end of Si waveguides with a butt coupling scheme. This integration scheme calls upon the selective epitaxial growth of pure Ge into a silicon-etched cavity localized at the end of the waveguide. In comparison with more conventional detectors using n-type and p-type implantations into the germanium layer, the implantation is performed beforehand in pure Si. The intrinsic width of the diode is then defined solely by the width of the Ge cavity. Such a double $\mathrm{Si} / \mathrm{Ge} / \mathrm{Si}$ heterojunction photodiode has the following advantages: i) a reduction of the number of technological steps (e.g. a reduction of the fabrication cost and complexity), ii) A decrease of the contact access resistance thanks to the use of a NiSi silicide, iii) an improvement of the optoelectronic device integration because identical silicide-based contacts are used for Si devices including both optical modulators and photodetectors.

Figure 1a shows a SEM cross-section of the $\mathrm{Si} / \mathrm{Ge} / \mathrm{Si}$ heterojunction photodiode and of the plug landing on the NiSi layer for this device fabricated in $200 \mathrm{~mm}$ Leti's $200 \mathrm{~mm}$ cleanroom. The width of the Ge layers varied from $300 \mathrm{~nm}$ to $1 \mu \mathrm{m}$. Figure 1c shows a simulation of light propagating from a Si waveguide into such a germanium photodetector. The use of SiGeSi heterojunction enables a better light confinement into the Ge layer than a full Ge integration [5,6]. Indeed, due to the refractive index difference between $\mathrm{Si}$ and $\mathrm{Ge}$, the light coupled into Ge does not spread out. Extra optical loss into doped contacts is then reduced, leading to improved responsivity of the photodetectors. 
(a)

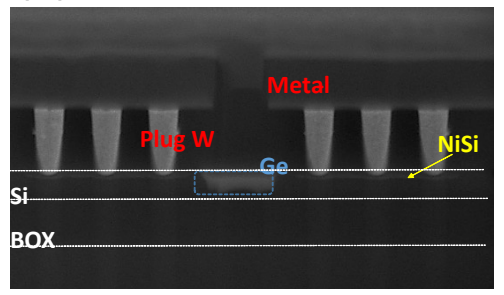

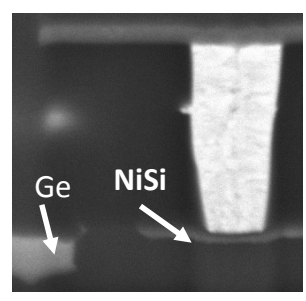

(b)
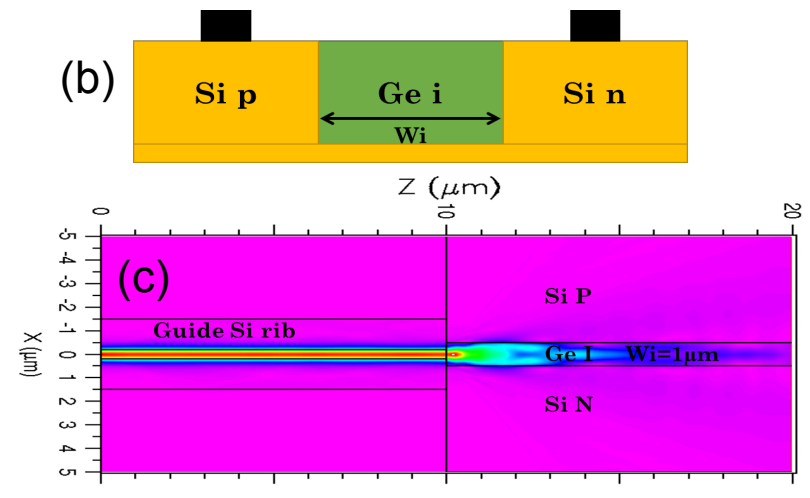

Fig. 1: (a) Cross-sectional SEM image of a fabricated Si/Ge/Si heterojunction based diode, (b) Schematic view of the diode. Wi is the intrinsic width of the diode. (c) Simulation of light propagation from a Si waveguide into a Ge layer surrounded by N-type and P-type Si contact regions.

\section{Results}

The dark current-voltage (I-V) characteristics of such waveguide $\mathrm{Si} / \mathrm{Ge} / \mathrm{Si}$ photodetectors were probed. Fig. 2a shows the evolution of the dark current in reverse bias as a function the detector length. Dark currents were lower than $400 \mathrm{nA}$ for voltages higher than $-4 \mathrm{~V}$.
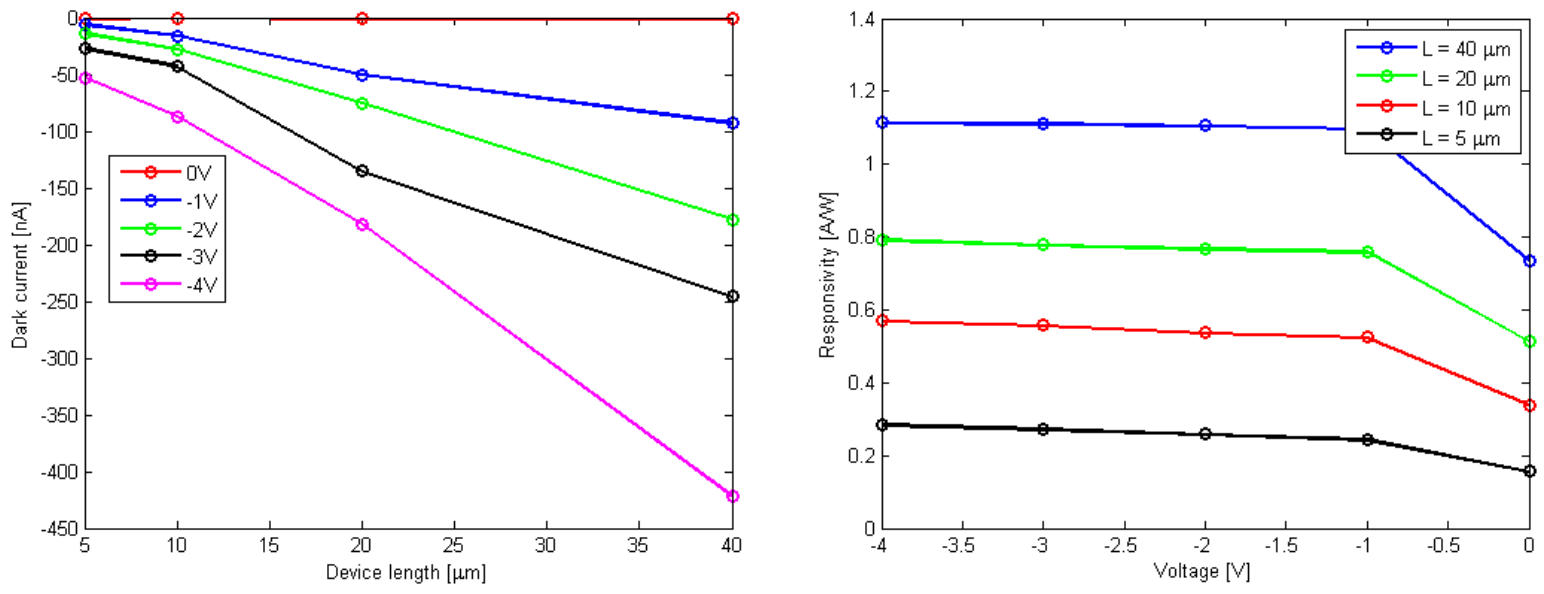

Fig. 2. (a) Dark current as a function of the photodetector length for several reverse bias voltages. (b) Responsivity as a function of the reverse bias voltage for several photodetector lengths.

Fig. $2 \mathrm{~b}$ shows the evolution of the responsivity with the device length and the reverse bias at a wavelength of $1.55 \mu \mathrm{m}$. The longer the photodetector and, to a lesser extent, the higher the voltage are, the higher the responsivity is. A maximum responsivity of $1.1 \mathrm{~A} / \mathrm{W}$, close to the theoretical limit, was achieved for a device length of $40 \mu \mathrm{m}$. We can also notice that the responsivity at $0 \mathrm{~V}$ was quite low. It reaches a sort of plateau for reverse bias voltages higher than $-1 \mathrm{~V}$. Such a behavior is mainly due to the energy potential barrier at the $\mathrm{Si} / \mathrm{Ge}$ heterojunction which reduces the electric field at $0 \mathrm{~V}$.

The $-3 \mathrm{~dB}$ bandwidth was determined using a classical RF experiment set-up. A linearly TE polarized light beam at a wavelength of $1.55 \mu \mathrm{m}$ was coupled into the waveguide. The integrated photodetector was biased using microwave probes up to $50 \mathrm{GHz}$ and the optical responses were measured using a lightwave component analyzer. Optical bandwidths higher than $50 \mathrm{GHz}$ were obtained for all waveguide $\mathrm{Si} / \mathrm{Ge} / \mathrm{Si}$ photodetectors allowing $40 \mathrm{Gbit} / \mathrm{s}$ operation in the $1.3 \mu \mathrm{m}-1.55 \mu \mathrm{m}$ wavelength range. 


\section{Conclusions}

A new and efficient waveguide $\mathrm{Si} / \mathrm{Ge} / \mathrm{Si}$ photodetector fabrication scheme was proposed that eases device integration into the silicon platform thanks notably to the use of the same doping levels and silicide steps for photodetectors and modulators. The advantages compared to conventional pure Germanium devices are: cost reduction, better responsivity, improved access resistance and process robustness. State of the art characteristics were obtained in terms of dark current, responsivity, and bandwidth.

In order to increase the sensitivity of photodetectors and reduce the overall power consumption of the optical link, such $\mathrm{Si} / \mathrm{Ge} / \mathrm{Si}$ heterojunction based photodetectors were operated in the avalanche mode. Gains were evidenced, in line with previous results for full waveguide Ge pin detectors [10].

Acknowledgement: The research leading to these results has received funding from the European Community's Seventh Framework Program (FP7/2007-2013) under grant agreement $n^{\circ} 318178$-PLAT4M an the European Research Council (ERC) un- der the European Union's Horizon 2020 research and innovation program (ERC POPSTAR - grant agreement No 647342).

\section{References:}

[1] D. Thomson et al. Roadmap on silicon photonics, J. of Optics 073003 (7), 2016

[2] Sun, C. et al. Single-chip microprocessor that communicates directly using light, Nature 528, 534-538 (2015)

[3] Handbook of Silicon Photonics (eds Vivien, L. \& Pavesi, L.) (CRC Press, 2013)

[4] JW. Silverstone et al., Silicon quantum photonics, IEEE J. Selected Topics in Quant. Elect. 22(6), 6700113 (2016)

[5] L. Vivien, et al. Zero-bias 40Gbit/s germanium waveguide photodetector on silicon. Opt. Express 20, 1096-101 (2012).

[6] L. Vivien, et al. $42 \mathrm{GHz}$ p.i.n Germanium photodetector integrated in a silicon-on-insulator waveguide. Opt. Express 17, 6252-7 (2009).

[7] T. Yin, et al. $31 \mathrm{GHz}$ Ge n-i-p waveguide photodetectors on Silicon-on-Insulator substrate. Opt. Express 15, 13965 (2007).

[8] T. Torikai, et al. 40-Gbps high-sensitive waveguide photodetectors. 6020, 602024-602024-8 (2005).

[9] C.T. DeRose, et al. Ultra compact $45 \mathrm{GHz}$ CMOS compatible Germanium waveguide photodiode with low dark current. Opt. Express 19, 24897-904 (2011).

[10] L. Virot et al. Germanium avalanche receiver for low power interconnects, Nature Comm. 5, 4957 (2014) 